\title{
REPRESENTACIONES SOCIALES DE ESTUDIANTES PERUANOS EN LA UNIVERSIDAD ESPAÑOLA
}

\author{
DUNIA SAMAMÉ \\ Universidad Nacional Mayor de San Marcos, Lima (Perú).
}

\section{RESUMEN}

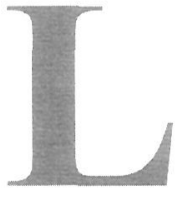

a movilidad humana referida a la educación multiplica las opciones de estudio, genera ciclos de nomadismo académico y representa para los estudiantes de los países periféricos el reforzamiento de su perfil profesional con el objetivo de mejorar sus posibilidades de inserción en el mercado laboral. En general, los flujos migratorios han diseñado nuevas realidades socio-culturales en el interior de los países receptores, convirtiendo las capitales de Europa, por ejemplo, en espacios mestizos y culturalmente plurales.

Palabras clave: migración peruana, Universidad, España, representaciones sociales.

\section{INTRODUCCIÓN}

En esta investigación, analizaremos el proceso migratorio de los estudiantes peruanos que cursan el tercer ciclo en la Universidad española de Alicante. En primer lugar, señalaremos una visión general sobre la movilidad por estudios, para, posteriormente, analizar, desde las perspectivas de los jóvenes estudiantes, las representaciones sociales sobre su proceso migratorio, entendidas como construcciones simbólicas que dan sentido y recrean la interacción social.

El trabajo de campo se basó en la metodología cualitativa, recolectando información entre los estudiantes becados, hombres y mujeres peruanos que actualmente cursan estudios del tercer ciclo (doctorados) de diferentes especialidades en la Universidad de Alicante. Se realizó en dos etapas: en la primera, se usó la observación participante y se aplicó entrevistas a profundidad, en la segunda, se realizó un grupo focal mixto para promover la discusión en base a temas que salieron de las mismas entrevistas.

\section{ESTUDIOS DE POSTGRADO}

En la Unión Europea, el interés por reformar el sistema universitario se ve reflejado en los esfuerzos por homologar los sistemas de educación superior, 
específicamente a través del Tratado de Maastrich (1992), las Declaraciones de La Sorbona (1998), Bologna (1999), Lisboa (2000), Estocolmo (2001) y Barcelona (2002).

La realización de estudios de postgrado suele ser el vínculo inicial que une espacios de investigación y desarrollo de universidades de países desarrollados con los países de origen de los estudiantes, mediante una selección de los alumnos más destacados, fomentando el inicio de una emigración que puede ser definitiva.

La internacionalización del medio académico, en el marco de las migraciones internacionales se traduce en la creciente movilización de estudiantes universitarios. El interés por propiciar la incorporación de estudiantes extranjeros se refleja en las políticas de becas, que facilitan la inmigración calificada a los países desarrollados, todo lo cual revela la importancia del conocimiento como elemento transformador en el desarrollo de la sociedad.

En sus orígenes, los postgrados en América Latina surgieron a partir de la consolidación de los Sistemas de Ciencia y Tecnología. Actualmente, el sistema de postgrado en las universidades públicas y privadas abarca estudios de especialización, maestría y doctorado. En general, se observa una mayor cantidad de alumnos en las especializaciones y maestrías, pues la realización de un doctorado tiene como requisito haber superado los estudios de maestría sustentados por la tesis de grado.

El sistema universitario en el Perú, en relación a los estudios de postgrado, presenta básicamente tres limitaciones: la primera es que ofrece una reducida cantidad de programas y muchas veces no brinda especializaciones específicas por áreas académicas en ciencias y letras, la segunda es que pocas instituciones disponen de un sistema de becas para realizar estos estudios y la tercera es el financiamiento para la efectiva realización de investigaciones de calidad, para lo cual se requieren una infraestructura específica para la producción de conocimientos. Esta problemática se experimenta tanto en las instituciones privadas como en las públicas, aunque en estas últimas también se libran batallas con respecto a la autonomía universitaria. No obstante, en el Perú, la cobertura del sistema educativo ha tenido avances significativos. En los últimos años, se ha experimentado un acelerado proceso de creación de universidades en todo el país, producto de la nueva Administración política y del impulso de los movimientos regionales.

TABLA 1: Perú, universidades creadas por décadas al año 2000

\begin{tabular}{|l|c|c|c|}
\hline \multicolumn{1}{|c|}{ AÑOS } & TOTAL & $\begin{array}{c}\text { UNIVERSIDADES } \\
\text { PUBLICAS }\end{array}$ & $\begin{array}{c}\text { UNIVERSIDADES } \\
\text { PRIVADAS }\end{array}$ \\
\hline Antes de 1960 & 10 & 9 & 1 \\
$1960-1969$ & 20 & 11 & 9 \\
$1970-1979$ & 5 & 5 & - \\
$1980-1989$ & 13 & 2 & 11 \\
$1990-1999$ & 25 & 2 & 23 \\
$2000-2009$ & 4 & 2 & 2 \\
\hline TOTAL & 77 & 31 & 46 \\
\hline
\end{tabular}

Fuente: Dirección de Estadística e Informática ANR Fecha: Septiembre-2000 
A pesar del aumento de la oferta académica, las posibilidades materiales y académicas de estas instituciones no superan, en algunos casos, los niveles mínimos de calidad, lo que ha propiciado el cierre de alguna de ellas. No obstante estas limitaciones y la dificultad de encontrar un puesto de trabajo acorde con el esfuerzo y la inversión realizada, la opción universitaria es dominante en relación al seguimiento de las carreras técnicas. Esto explica el sobrepoblamiento universitario. Continuar estudios de postgrado significa, en muchos casos, desplazarse a la capital, pues en Lima se concentra el mayor número de universidades, acentuando, en este caso, el centralismo académico. Asimismo, los estudios de doctorado presentan menos variantes, en relación a las maestrías, lo cual reduce significativamente las opciones.

TABLA 2: Universidades de Perú. Facultades, Carreras profesionales, II Especialización, Maestría y Doctorado según Eniversidad. 2000.

\begin{tabular}{lccccccc}
\hline UNIVERSIDAD & ACULTAD & $\begin{array}{c}\text { CARRERA } \\
\text { PRO ESONAL }\end{array}$ & II ESPECIALI & ACI N N & MAESTRIA & DOCTORADO & OTROS \\
\hline PÚBLICA & 301 & 621 & 36 & 212 & 17 & 14 \\
\hline PRIVADA & 175 & 461 & 19 & 120 & 16 & 2 \\
\hline TOTAL & $\mathbf{4 7 6}$ & $1 \square \square \square$ & $\square \square$ & $\square \square \square$ & $\square \square$ & $\mathbf{1 6}$ \\
\hline
\end{tabular}

Fecha: Septiembre - 2000. Fuente: dirección de Estadística e Informática. ANR

Estos y otros motivos son los que pesan para que muchos jóvenes y sus familias definan la migración como una posibilidad de lograr mejor calificación. Los flujos de migración interna en el país transforman el espacio urbano. La atracción que la capital genera en los migrantes provincianos incrementa las demandas sociales, una de ellas el acceso a la educación de calidad. La valoración positiva de la educación superior se percibe como una herramienta vital para la inserción en el mercado de trabajo. En ese sentido, también es importante mencionar el estímulo fomentado desde las familias.

En el marco de la sociedad de la información, la movilidad por estudios hace más competitiva la oferta en las universidades de acogida. Es el caso del sistema universitario español, que viene atravesando un proceso de reestructuración, explicado por diversas variables: las tasas demográficas, la presencia de universidades privadas, la significativa aceptación de los estudios a distancia -como es el caso de la UNED y la UOC-, factores que influyen en el descenso de la matrícula de estudiantes universitarios y que motivan que las universidades promocionen más activamente su oferta de estudios a través de diferentes mecanismos, como promover programas en red, enseñanza continua para el adulto mayor, realización de jornadas de puertas abiertas para los estudiantes de Bachillerato, captación de alumnos extranjeros con diversos programas de tercer ciclo, etc.

Los avances tecnológicos y científicos de la sociedad de la información facilitan el acceso a la oferta educativa internacional. España, al compartir el mismo idioma, se convierte en el destino preferido para las migraciones de los países de América Latina, donde, por lo general, la migración por estudios se asume como un signo de superación y logro personal. La globalización acelera la internacionalización de los sistemas de educación superior, de ese modo la investigación constituye un desafío para los países que buscan salir 
del subdesarrollo. Los beneficios de la circulación, de la interacción con pares de diferentes regiones del mundo o la participación en eventos científicos de carácter internacional constituyen objetivos básicos de la actividad académica. Bajo estas premisas se vienen estableciendo diversos programas de estímulo al intercambio y circulación en el nivel académico.

\section{MIGRACIÓN EN BUSCA DE CALIFICACIÓN}

La bibliografía sobre la migración calificada, en su mayor parte, está relacionada con los enfoques teóricos del push/pull (empuje y atracción) y el brain drain (drenaje de cerebros). Ambos suponen el traslado de individuos altamente calificados de países "en vías de desarrollo" hacia las "naciones industrializadas". Estas diásporas científicas son una pérdida de capital humano para el país emisor. Por otro lado, desde la propuesta teórica de la comunidad transnacional (redes de relaciones para migrar por estudios), se toma como base el impacto de las nuevas formas de comunicación y el avance de los recursos tecnológicos que amplían las limitaciones del ámbito universitario y permiten conocer la oferta educativa internacional. Así, tenemos que existen visiones optimistas y pesimistas, planteadas en términos de pérdidas y ganancias. En todos los casos estamos hablando de movilidad de estudiantes con características variables y con trayectorias migratorias circulares, pendulares y con retornos transitorios. Un estudio de mayor profundidad requerirá identificar esas trayectorias para evaluar el vínculo entre los emigrantes y el país de origen en términos de intercambio y considerando los grados de retorno. También el tipo de inserción de los emigrantes permitirá diferentes posibilidades de intercambios con los países de origen; por su parte, éstos despliegan diversos esfuerzos por desarrollar políticas de revinculación.

España tiene convenios con universidades de América Latina mediante los que los estudiantes latinoamericanos acceden a los programas de becas de la Agencia Española de Cooperación Internacional, a los programas ALFA, ALBAN, ERASMUS, etc., todos ellos orientados a fomentar la movilidad de estudiantes, estableciendo acciones cooperativas entre los centros universitarios de origen y destino. Asimismo, algunas universidades cuentan con programas de cooperación internacional a través de los cuales proporcionan subvenciones para proyectos y becas, como es el caso de la Universidad de Alicante.

\section{REPRESENTACIONES SOCIALES SOBRE EL PROCESO MI- GRATORIO. ETAPA PREVIA}

Trabajar con las representaciones sociales significa analizar los mundos de significación que se producen con y a través del lenguaje. Nos acercamos a un nivel de construcción de sentidos que recrea el mundo a través del sistema complejo de representación (Barón Porra, 2001). El lenguaje actúa como vehículo indiscutible en la narrativización de la realidad, por ello constituye un componente básico de las representaciones sociales. El proceso de simbolización de los becarios peruanos está arraigado en las prácticas asociadas 
al proceso de socialización universitaria adquirido previamente, ahora en un contexto distinto

Las representaciones sociales son formas de interpretación y simbolización de aspectos clave de la experiencia social. Estas representaciones se originan y a la vez inciden en las formas de "ver el mundo" o interpretar la experiencia, orientando las prácticas sociales de los actores. Sin duda, las dimensiones biográficas explicarían con mayor precisión las divergencias entre las representaciones y los tipos de socialidad que se crean entre los estudiantes latinoamericanos.

En la base del proceso migratorio por estudios se encuentra la idea compartida por los jóvenes de expandir sus horizontes accediendo a un espacio académico que les permita el perfeccionamiento profesional deseado; al mismo tiempo representa para ellos la posibilidad de conocer otras culturas.

Estos jóvenes pertenecen, por lo general, a la clase media, son titulados, poseen calificaciones óptimas y muchas ganas de mejorar su situación económica, por lo general, insertos en el mercado laboral de su país de origen y con altas aspiraciones de superación profesional. El entorno familiar presenta casos particulares de profesionalización en los padres o en algún otro pariente. Al mismo tiempo, son percibidos como un ejemplo de superación personal por el resto de los hermanos. En su mayoría, han superado el nivel de estudio de los padres.

\subsection{En la Embajada..., de lo peor...}

Una opinión, una imagen o un prejuicio permiten formular juicios, ideas, representaciones sobre algo o alguien. Aunque esa aproximación pueda ser distorsionada es la que hará posible otras aproximaciones, otros juicios, (Canessa, 2003). En ese sentido, iniciar la tramitación de las visas supone enfrentarse a distintos prejuicios basados enun trato discriminatorio.

Sin duda, una de las primeras dificultades, y motivo de conflicto, que deben padecer los estudiantes y cualquier otro ciudadano, es iniciar los trámites para obtener la visa en la Embajada de España; un predicamento que se vuelve a veces inacabable, donde la mayoría, pese a contar con la carta de aceptación de las universidades de acogida y el financiamiento respectivo, por lo general, es víctima de malos tratos y desplantes del personal administrativo:

"Bueno, la primera vez, vi que, cuando ellos no saben que tú vas a venir por estudios, te tratan mal. Piensan que la gente viene a buscar trabajo, bueno los españoles están acostumbrados a eso. Pero cuando le mostré la concesión de la beca, fue un poco mas amable." WaLTER.

El caso es el mismo tanto para mujeres como para hombres, sin embargo, al mencionar que se trata de becarios:

"El tratamiento que te da la embajada es brutal, que quede bien claro, es brutal, porque era becaria me trataron menos mal, eso deberia cambiar." MARGOT.

En otro testimonio, la impresión es la misma: 
"Yo fui por un trámite puntual porque ya tenía la beca, pero, naturalmente, la imagen que todavia tengo clara es una imagen de maltrato al público, de carencia absoluta de cualquier sentido mínimo de la función publica y de ineptitud. La idea es que la gente haga cola. Cuando desde cualquier punto de vista eso implica ineficacia y maltrato $y$, sobre, todo una distancia radical entre el discurso exterior del Estado español y las funciones que en concreto realizan sus representantes en otros paises". José.

\subsection{Tienes que tener paciencia y mandar tus papeles, a lo mejor te liga}

Por lo general, los jóvenes realizan varios intentos de postular a becas. Muchos de ellos ya tienen experiencia armando expedientes y evaluando los beneficios de la oferta educativa. En algunos casos, la férrea decisión de migrar para continuar sus estudios los lleva a realizar continuos esfuerzos, esperando tener suerte, pero sin sostener un optimismo desbordante. Sin duda los avances tecnológicos y las ventajas de las postulaciones on line facilitan el acceso a distintas opciones. Los más experimentados consideran que obtener la admisión en la universidad española es relativamente sencillo, se trata de tener paciencia y hacer una inversión para enviar los documentos necesarios para concretar el ingreso. Las complicaciones surgen al buscar el financiamiento: son muchos los casos de estudiantes ya admitidos que han debido desistir por falta de dinero.

"Tenia otras admisiones, pero no pude tomarlas por el financiamiento. Luego me informé por Internet que la Universidad de Alicante tenía becas para la especialidad que me interesaba". JuaN.

\subsection{Como es el mismo idioma...}

Las motivaciones para continuar estudios en el extranjero se vinculan directamente con las escasas posibilidades de continuar su formación académica en instituciones del propio país que ofrezcan postgrados de interés. En algunos casos, los jóvenes ya cuentan con estudios de postgrado, pero consideran que el nivel obtenido es insuficiente. Testimonios como el siguiente ponen en evidencia estas cuestiones:

"No habia un doctorado dentro de las universidades peruanas en la rama que yo estudio (Agronomia). Las únicas oportunidades eran Norteamérica, descartado por que necesitas fluidez en el idioma inglés, y la otra alternativa Europa, especificamente España".

JUAN.

El uso del lenguaje abre posibilidades de ser en el mundo, funciona como un marcador social, de allí que los inmigrantes lo perciban como un elemento de apropiación por excelencia, pues, de acuerdo a su uso, se puede acelerar o no el proceso de adaptación; los cambios culturales, la diferencias y limitaciones se visualizan de forma más evidente a través de su uso. La elección del país se debe básicamente a la compatibilidad del idioma

"Hay muchas cosas curiosas. En general, nos entendemos bien, pero siempre hay cosas, por ejemplo, eso de venga, y yo seguía a la persona 
que me decia eso, o que hablen a veces casi gritando, luego te acostumbras." Jost́.

\subsection{Tienes que adaptarte, no te queda de otra}

En tanto unidades de sentido, las representaciones sociales "organizan" la percepción de la experiencia, del mismo modo en que lo hacen, por ejemplo, las categorías analíticas en las formulaciones teóricas (Mato, 1999).

A la satisfacción de haber obtenido una beca, le sigue la preocupación por cómo será su futuro una vez insertados en un ambiente académico foráneo, sobre todo en los casos en que representa la primera vez que deben salir de su pais.

"Lo primero que hice fue presentarme ante la oficina de cooperación internacional de la Universidad. Ellos me ubicaron en un lugar donde quedarme un piso, junto con algunos otros compañeros que vine. Ni bien llegado, ellos me integraron a la Universidad. Eso es lo bueno: no dejan libre o lo abandonan a uno: "ya bueno, acá está", sino que tratan de ubicarlo, al menos, si es extranjero hasta que se adecue completamente". Daniel

Se trata entonces de ajustar voluntariamente los comportamientos a los valores, normas, reglas y convenciones sociales al nuevo contexto.

\subsection{Somos parecidos, pero aqui hay orden y respeto por lo ajeno}

Los becarios peruanos comparten la idea de dar una buena impresión en su calidad de becarios. Es por ello que tienen muy marcado el grado de responsabilidad que representa que sus estudios estén financiados, si bien el idioma es el mismo y la integración al nuevo entorno es relativamente sencilla. Los testimonios destacan la tranquilidad y el clima de confianza que les brinda la universidad. En general, el estilo de vida de los españoles les parece similar a la de los peruanos, aunque cueste acostumbrarse a algunos detalles pintorescos.

"Somos parecidos. Por ejemplo, el machismo, son violentos con su parejas; pero también acá la gente es muy respetuosa del otro, también son ordenados, el bus llega más menos a la hora, la gente respeta un poco lo ajeno". WALTER.

\subsection{La educación en el Perú es más exigente}

Dependiendo de la institución de procedencia, universidades públicas o privadas, varían las opiniones sobre el sistema universitario español. Por lo general, se destaca mucho las facilidades logísticas y de infraestructura que tienen a su disposición. Por el lado académico, también hay un reconocimiento sobre la calidad de los estudios que vienen recibiendo:

"El sistema es diferente, nosotros tenemos un sistema más americano de dictar las clases y las prácticas y llevarlas con mayor exigencia, llevar las clases. Las clases de maestría eran más exigentes que las clases de doctorado aqui". ALßERTO. 
"Como te decía, la cantidad y el costo de los equipos que tienes acá supera largamente cualquier cosa que pueda haber allá”. DAviD.

La educación en el Perú alienta una adaptación jerárquica y formalizada, enfatizando y reproduciendo los valores culturales dominantes. En esas condiciones, no hay futuro para desarrollarse, tarde que temprano se terminará siendo arrastrados por la corriente, agobiados por la incertidumbre y sin razones para intentar algo más. Continuar los estudios fuera se vuelve una vía para el logro de metas que conducen a la movilidad, el ascenso, el progreso social, trayendo con ello mejores ingresos, contribuyendo al desarrollo y a la realización personal.

\subsection{Los españoles son excelentes compañeros...}

En las relaciones interpersonales se evocan las representaciones a través de las identidades sociales que se ponen en juego en la interacción. Estás representaciones sociales se caracterizan por su dinamismo y constante reconfiguración.

Uno de los elementos más destacados por los becarios peruanos es el grado de comprensión de sus compañeros españoles, pues, aunque las costumbres generan desacuerdos, éstos son superados con facilidad:

"Mis compañeros españoles son gente magnifica. Yo creo que ellos, al inicio, creen que, como peruano, uno viene a trabajar, ir a la construcción o al campo a recoger los frutos. Entonces, ellos se sorprendían de que yo les decía que habia venido a estudiar. Ahora han pasado casi dos años, la relación con ellos es muy buena, sin embargo, hay algunos que creen que en el Perú hay computadoras, hay gente que cree que por vivir en el primer mundo ya lo saben todo, pero hay gente que ha leido apenas algunas ciertas cosas". WALTER.

\subsection{En las noticias, del Perú sólo llega lo peor}

Recordar el Perú genera nostalgia, malestar e impotencia, refuerza afectos identitarios a la distancia:

"Veo con pena al Perú, de estar tan lejos y no poder hacer nada. Cuando voy a Perú tengo ilusión de hacer algo por mi Universidad, por mi centro de trabajo y, luego, llegas y te encuentras con que nada cambia, desde el gobierno, la corrupción, sigue habiendo una situación de injusticia y olvido de los más pobres".

Por lo general, estos jóvenes desean preparase mejor para, tal vez, en un futuro, incursionar en la política peruana o asumir cargos públicos. En lo fundamental, quieren revertir esas experiencias en beneficio de su país, en ese sentido, en los entrevistados se identifican con la idea de hacer algo por su gente.

"Yo creo que eso afecta bastante, las noticias que llegan, los problemas que hay entre los políticos, eso llega muy pronto. Yo sé que en España no saben lo que es el Perú, lo valioso de ser estudiante, de gente que. está alli esforzándose, de madres de familia que se rajan la vida para. mantener a sus hijos. Eso no se sabe. Yo he escrito varias veces al 
embajador Olivera, diciéndole que tenemos que cambiar la imagen, le mandé propuestas, proyectos, pero el señor está más preocupado en sus cosas". ENRIQUE.

\subsection{Ser becario es un privilegio}

Son diversas las becas por las cuales los estudiantes peruanos han accedido a la Universidad de Alicante, la dotación económica, por lo tanto, es diferente; sin embargo, en conjunto, podemos señalar que tienen todas las comodidades para dedicarse exclusivamente a los estudios.

Los becarios peruanos no se perciben a sí mismos como emigrantes. Consideran que su situación es provisional y básicamente responde a la necesidad de perfeccionamiento académico. Sin embargo, muchos de ellos ven la posibilidad de establecerse de forma definitiva en España. Por otro lado, los circuitos en los cuales se desenvuelven se circunscriben al entorno académico, sus amigos próximos son otros latinoamericanos.

"Alli, en ese sentido, el cambio es total. Al menos, dentro de la Universidad, están en las mismas condiciones de competitividad que un español o que otro profesional, no hay ningún tipo de diferencia". DANIEL.

Sin duda, todos comparten la idea de que el elemento más positivo de la Universidad de Alicante es la disposición de un campus universitario óptimo, además del acceso a la información:

"... a parte de los medios de información y la infraestructura, la calidad humana e intelectual de muchas personas ". José.

Si tomamos en conjunto los aspectos desarrollados, podemos afirmar que el éxito académico, desde las representaciones de los estudiantes, se define fundamentalmente como un proceso de adaptación que el estudiante debe asumir al ingresar a una facultad, acompañado de diversas reglas que se deben conocer y saber manejar adecuadamente, a la manera de un juego que se va definiendo al mismo tiempo que se juega.

En general, sienten que su experiencia es provechosa, conocen muy bien las instituciones y convocatorias a becas y financiamiento de proyectos. Con estos conocimientos, animan a otros compatriotas o familiares a intentar salir del país y compartir esa experiencia.

"Yo creo que las fronteras las han hecho para manipular a la gente, para dividirla más y sentirse más poderosos. Todos estamos en el derecho de cruzar esa frontera y ver qué hay más allá. Viajando se nos quitan los mitos que nos han sembrado en la cabeza cuando nos educaron, pero esos mitos siguen viviendo. Hay compañeros que, cuando le dices me voy a Europa, acá se dicen $U y$... que es algo maravilloso, pero también hay quienes regresan al Perú sintiéndose que ya han pisado el paraíso. Acá se vive un poco mejor, pero simplemente eso". WALTER

En general, consideran que son respetadas sus opiniones y que, en realidad, la universidad española les proporciona todos los mecanismos para desarrollarse en sus áreas de investigación y estudio. Aquellos que se desempeñan en el área de ciencias definitivamente destacan las facilidades y la infraestructura. 
Los que están por cumplir el periodo de la beca, se preocupan por la sustentación del DEA y por la renovación de la beca y los que ya están culminando estudios se plantean el dilema entre regresar al país o ver las posibilidades de quedarse o intentar otra beca.

El carácter adaptativo del éxito de los estudiantes peruanos radica en tener un aprendizaje rápido de las reglas de la vida académica y social. En las rutinas y organización del tiempo, se caracterizan por su dedicación al estudio, privilegian su permanencia en la Universidad, las bibliotecas, los laboratorios, se autodisciplinan. La principal motivación es el compromiso con lo deseado, ponen a prueba sus capacidades y se imponen jornadas prolongadas de investigación, lectura, productividad académica, sus tiempos de ocio son mínimos.

\subsection{Los migrantes laborales la pasan mal...}

La creciente movilidad de las personas y las facilidades para desplazarse hacen de la inmigración una de las prioridades del debate político. Ante este nuevo escenario se estimulan resistencias y prejuicios sobre la figura del "otro", del "diferente", vinculadas a la migración legal e ilegal. En este marco, los estudiantes becados representan una preocupación menor, pues, debido al carácter temporal de su proceso migratorio, no compiten directamente en el mercado laboral; aunque debemos anotar que, en muchos casos, esta primera experiencia se consolida en una residencia permanente o se convierte en un estilo de vida que los transforma en viajeros permanentes, siempre a la caza de opciones de estudio a través de sistemas de becas.

La migración peruana a España tiene una larga tradición, es por ello que resulta familiar la presencia de estudiantes peruanos, no es así en el caso de otros becarios. Ahora debemos resaltar que los testimonios diferencian entre la situación del inmigrante legal e ilegal y la condición particular de estudiantes becados.

"Mucha gente de Latinoamérica viene a trabajar como albañiles, meseros. Yo he tenido que trabajar de mesero en una época que estuve mal económicamente y el racismo y discriminación era constante. Pero en la Universidad no, al contrario, aqui detestan mucho ese tipo de expresiones".

Por lo general, las opiniones se concentran en los inmigrantes ilegales. En relación a los latinos, se reconoce que, mayoritariamente, vienen como mano de obra para oficios menores.

"Aqui hay una clasificación de quienes son los peores, y eso fastidia. Yo soy peruana, pero también soy extranjera. Por ejemplo, los marroquies y los árabes son vistos como delincuentes, que te pueden robar, "cuida el bolsillo y eso". Luego los ecuatorianos, que son la mayoría, ellos son vistos como la mano de obra barata. Y luego también están los bolivianos y me da pena la situación de los colombianos, ellos están vistos como narcotraficantes y argentinos también hay mucho, pero si de ellos no he escuchado nada". MARGot. 


\subsection{Trabajaria por mi país, quisiera hacer algo por el Perú...}

Por lo general, las aspiraciones de los estudiantes se proyectan en tres sentidos:

1) los que quieren regresar al Perú y trabajar, invirtiendo los conocimientos adquiridos en el extranjero,

2) aquéllos que ven las posibilidades de conseguir otras becas de estudio para continuar su perfeccionamiento académico y

3) aquéllos que ven las posibilidades de quedarse en España y trabajar en sus respectivas áreas.

Sin embargo, todas estas posiciones comparten la idea de entregarlo todo por el país y de que, si en verdad deben hacer un sacrificio, deberían hacerlo en su patria, no trabajar en cualquier trabajo eventual que no les represente garantías de estabilidad económica.

"Depende, alli hay dos cosas, depende. Si tienes un trabajo definido, puedes enriquecer tu formación porque ya tenías algo definido en Perú, pero, para alguien que no tiene nada definido en Peri, yo me imagino que la condición es tan competitiva.. Da igual tener la formación peruana, española y argentina, todo depende de la competitividad del mercado en ese momento". JuAN.

Gran parte de los estudiantes ven su futuro alcanzando las metas que se propusieron al salir de su país. En el caso de las mujeres, su futuro no está marcado por un mandato tradicionalmente femenino, supeditadas a la manutención del marido, sino, por el contrario, se muestran distantes a establecer compromisos que impliquen renuncias a su desarrollo profesional. Por otro lado, los hombres sí se imaginan constituyendo una familia, pues no encuentran irreconciliable ese proyecto con su desempeño profesional, ni que implique una renuncia a su rol masculino.

"Me imagino viviendo en otro distrito, en Lima, con mi familia dándoles lo mejor a ellos. Yo, como catedrática en una Universidad, dando conferencias, charlas en otros países, en otros sitios y soltera". Rosario.

\section{BIBLIOGRAFÍA}

BARÓN PORRA, L.F.; VALENCIA, $M$. Representaciones sobre el conflicto en medios y audiencias. Bogotá. CINEP 2003.

CHARUM, J.; MEYER, J.B. El nuevo nomadismo cientifico. La perspectiva latinoamericana. Bogotá, Colombia Escuela Superior de Administración Pública, 1998.

CANESSA, G. El acceso a la educación superior en un contexto de crisis: su incidencia en la práctica de la orientación vocacional. Congreso Latinoamericano de Educación Superior en el Siglo XXI. 18, 19 y 20 de Septiembre de 2003, San Luis, Argentina.

ESTEFONI, C. Representaciones culturales y estereotipos de la migración peruana en Chile. Santiago de Chile, FLACSO, 2000.

MATO, D. "Prácticas transnacionales, representaciones sociales y (re) organización de las "sociedades civiles" en: América Latina en Tiempos de Globalización II, Caracas: UNESCOCIPOST (UCV), 1999. 
NADAL, J. El mundo que viene. Alianza Editorial. Madrid, 1994.

TUNNERMANN, C. Universidad y Sociedad (Balance histórico y perspectivas desde Latinoamérica). Caracas, Comisión de estudios de postgrado, UCV, /Ministerio de Educación, Cultura y Deportes, 2000. 